\title{
Germinação de sementes de genótipos de maracujazeiro
}

\author{
Rodrigo Sobreira Alexandre ${ }^{(1)}$, Américo Wagner Júnior ${ }^{(1)}$, Jacson Rondinelli da Silva Negreiros ${ }^{(1)}$, \\ Alexandre Parizzotto(1) e Claudio Horst Bruckner ${ }^{(1)}$
}

(1)Universidade Federal de Viçosa, Dep. de Fitotecnia, Av. P.H. Rolfs, s/no, CEP 36570-000 Viçosa, MG. E-mail: rsalexandre@click21.com.br, jacson@vicoca.ufv.br, parizzoto@bol.com.br, bruckner@ufv.br

\begin{abstract}
Resumo - O objetivo deste trabalho foi avaliar a germinação de sementes de 22 progênies de meios-irmãos e duas cultivares de maracujazeiro (Passiflora edulis Sims f. flavicarpa Degener) e submeter 6 desses genótipos a diferentes tempos de embebição. Foram conduzidos dois experimentos, sendo que no primeiro foi utilizado o delineamento inteiramente casualizado, com quatro repetições, considerando-se cada genótipo como um tratamento. No segundo experimento, utilizou-se o mesmo delineamento experimental, num fatorial 6x4 (genótipo $\mathrm{x}$ tempo de embebição), com quatro repetições. Cada grupo de 50 sementes foi considerado como uma unidade experimental. No primeiro experimento, aos 28 dias, avaliaram-se a porcentagem de germinação e velocidade de emergência e aos 45 dias, a porcentagem de sobrevivência, o comprimento total das plântulas, a altura das plântulas, o comprimento de raiz, o número de folhas e a massa total das plântulas. No segundo experimento, aos 28 dias, as mesmas variáveis do experimento anterior foram avaliadas, com exceção da porcentagem de sobrevivência e número de folhas. A porcentagem de germinação das sementes e o índice de velocidade de emergência não são influenciados pelos diferentes tempos de embebição, mas pelo genótipo das plantas, indicando que estas características podem ser utilizadas para seleção, no melhoramento genético.
\end{abstract}

Termos para indexação: Passiflora edulis, maracujá-amarelo, emergência, propagação sexuada.

\section{Seed germination of yellow passion fruit genotypes}

\begin{abstract}
The objective of this work was to evaluate the germination of seeds of 22 half-sib progenies and two cultivars of Passiflora edulis Sims f. flavicarpa Degener and submit 6 of these genotypes to different times of soak. Two experiments were carried out. The first experiment was set up on an entirely randomized design, with four repetitions, and each genotype was considered as a treatment. In the second experiment, the same experimental design was used, in a factorial $6 \times 4$ (genotype $\mathrm{x}$ time of soak), with four repetitions. In both experiments, each group of 50 seeds was considered as an experimental unit. In the first experiment, after 28 days, germination percentage and emergency speed were evaluated. After 45 days of survival the percentage, total plantlets and root length, plantlets height, number of leaves and total dry mass of plantlets were evaluated. In the second experiment, after 28 days, the same variables from the first experiment were evaluated, except survival percentage and number of leaves. The seed germination percentage and the emergency speed are not influenced by the different times of soak, but there is effect of plant genotype, indicating that these characteristics can be used for selection in genetic improvement.
\end{abstract}

Index terms: Passiflora edulis, yellow passion fruit, emergency, sexual propagation.

\section{Introdução}

O maracujazeiro é originário da América Tropical e possui mais de 150 espécies nativas do Brasil. As mais conhecidas e de maior aplicação comercial são Passiflora edulis Sims f. flavicarpa Degener e Passiflora edulis Sims.

A propagação do maracujazeiro pode ser realizada sexuadamente, por sementes, ou assexuadamente, por meio de enxertia, estaquia ou cultura de tecidos.
A propagação seminífera é a preferida entre os métodos assexuados, pela facilidade e antecipação da formação das mudas (Ferreira, 2000).

A qualidade fisiológica das sementes é influenciada pelo genótipo, sendo máxima na sua maturidade (Delouche \& Baskin, 1973). Prete \& Guerra (1999) também consideram que o máximo potencial de qualidade das sementes, como germinação, emergência e vigor de plântulas, seja controlado geneticamente. 
Muitas informações são conhecidas quanto à germinação de sementes do maracujazeiro, porém, é unânime a afirmativa de que o início e o término da germinação das sementes de Passifloráceas ocorrem de forma irregular, podendo, este período, ser de dez dias a três meses, o que dificulta a formação das mudas, por não serem uniformes (Akamine et al., 1956; Kuhne, 1968; Luna, 1984).

Algumas espécies apresentam dormência em suas sementes. Essa dormência consiste em um mecanismo de sobrevivência, pois pode retardar a germinação, que não ocorre quando as condições para o estabelecimento das plântulas são limitantes, além de permitir a distribuição das sementes germinadas ao longo do tempo, favorecendo sua sobrevivência (Ramos et al., 2002). Com a domesticação das plantas, ocorre seleção contra a dormência das sementes que, na maioria das espécies cultivadas, apresentam germinação rápida e uniforme. Morley-Bunker (1974) menciona que algumas espécies de Passiflora spp. apresentam dormência em suas sementes, ocasionada pelo mecanismo de controle da entrada de água, devido à dureza do tegumento, necessitando de tratamento para sua superação.

A água tem papel fundamental na compreensão da biologia da semente, particularmente nos processos de desenvolvimento e germinação (Villela, 1998). A hidratação de sementes maduras, secas e não dormentes estabelece o início do processo de germinação, possibilitando a reativação do sistema metabólico e a síntese de novos compostos (Labouriau, 1983). De acordo com Carvalho \& Nakagawa (1983), por meio do fornecimento da água ocorre a reidratação dos tecidos e a conseqüente intensificação da respiração e de todas as outras atividades metabólicas, que culminam com o fornecimento de energia e nutrientes necessários para a retomada do crescimento do eixo embrionário. Entretanto, Ferreira (1998) observou que sementes de P. edulis Sims f. flavicarpa, P. alata, P. giberti e $P$. caerulea não apresentam impedimentos à entrada de água, embora o tempo de embebição seja diferente em cada uma das espécies. Pereira \& Andrade (1994) também não observaram a necessidade de submeter sementes de $P$. edulis a tratamentos pré-germinativos.

A diversidade genética, no gênero Passiflora, é um fator fundamental. Nos estudos de melhoramento de plantas, principalmente em programas de seleção, essa diversidade pode ser investigada precocemente pela qualidade fisiológica das sementes, com os testes de vigor
(Dias \& Marcos Filho, 1995). Assim, o tempo médio de germinação e a sua uniformidade poderão proporcionar produção de mudas em escala comercial de maneira mais eficiente.

Nos trabalhos de melhoramento e em outras pesquisas, tem sido por vezes constatado que as sementes de algumas plantas não germinam bem ou o fazem de modo mais lento, apesar de coletadas e beneficiadas pela mesma técnica utilizada em sementes que não apresentam tais problemas.

O objetivo deste trabalho foi avaliar a germinação de sementes de diferentes genótipos de maracujazeiro.

\section{Material e Métodos}

Os trabalhos foram realizados no Dep. de Fitotecnia, da Universidade Federal de Viçosa, MG, no período de junho a setembro de 2003, com sementes extraídas de frutos maduros e bem desenvolvidos, de maracujazeiro (P. edulis Sims f. flavicarpa Degener).

$\mathrm{Na}$ extração das sementes, os frutos foram seccionados pela metade, retirando-se de sua cavidade interna a mucilagem que continha as sementes. A retirada do arilo foi realizada manualmente, por meio de fricção em peneira de malha fina, acrescentando-se cal virgem. Após a remoção, as sementes foram lavadas em água corrente e dispostas em papel toalha, onde permaneceram durante três dias, à sombra, para secagem. Em seguida, foram semeadas a uma profundidade de $0,5 \mathrm{~cm}$, em espaçamento de $2 \times 2 \mathrm{~cm}$ em caixas de

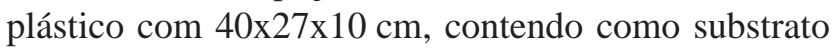
uma mistura de terra vermelha:areia $(1: 1 \mathrm{v} / \mathrm{v})$. As caixas foram dispostas em uma mesa de ripado suspensa, sob tela sombrite com $70 \%$ de incidência solar.

O trabalho foi dividido em dois experimentos, sendo que para compor o primeiro, foram coletadas sementes de vinte e duas progênies de meios-irmãos e duas cultivares de maracujazeiro (Tabela 1), no período de junho a julho de 2003. Utilizou-se delineamento experimental inteiramente casualizado, com quatro repetições, considerando-se como uma unidade experimental cada grupo de 50 sementes. A temperatura média do ar foi de $16,1^{\circ} \mathrm{C}$, variando entre $13,5^{\circ} \mathrm{C}$ e $20,2^{\circ} \mathrm{C}$.

Aos 28 dias, avaliaram-se a porcentagem de germinação e o índice de velocidade de emergência (IVE) (Maguire, 1962). Aos 45 dias foram avaliados a porcentagem de sobrevivência de plântulas após a germinação (\%), o comprimento total das plântulas $(\mathrm{cm})$, a altura das plântulas $(\mathrm{cm})$, o comprimento de raiz $(\mathrm{cm})$, o nú- 
mero de folhas e a massa da matéria seca total das plântulas (mg).

Os dados foram submetidos à análise de variância e ao teste de agrupamento Scott-Knott $(\alpha=0,01)$, sendo que todos os dados e análises correspondentes foram efetuadas com auxílio do programa SAEG. Os dados das porcentagens de germinação e de sobrevivência foram transformados em arco seno $\sqrt{\mathrm{x} / 100}$ e o número de folhas em $\sqrt{\mathrm{x}+1}$. Os dados das demais variáveis não sofreram transformação. O IVE foi estabelecido com o teste de emergência e suas avaliações realizadas, diariamente, a partir do surgimento das primeiras plântulas normais, verificando do $18^{\circ}$ dia após a semeadura até o $20^{\circ}$ dia.

Com base nos resultados alcançados no primeiro experimento, realizou-se um segundo experimento de agosto a setembro de 2003, em que se buscou escolher aqueles que apresentaram respostas representativas, ou seja, escolheram-se dois genótipos com taxa de germinação maior ou igual a $60 \%$ (genótipos 6 e 14), dois com entre $10 \%$ e $60 \%$ (genótipos 36 e 42) e dois com germinação inferior a $10 \%$ (genótipos 8 e 18). Foram coletadas sementes de cinco progênies de meios-irmãos (genótipos $6,8,14,18$ e 36) de uma cultivar (genótipo 42), as quais foram escarificadas mecanicamente com lixa noำ, sendo posteriormente embebidas em água destilada em quatro diferentes tempos $(0,12,24$ e 48 horas), procurando-se, assim, retirar o efeito da dormência pela entrada de água. A temperatura média do ar foi de $17,7^{\circ} \mathrm{C}$, variando entre $12,9^{\circ} \mathrm{C}$ e $24,6^{\circ} \mathrm{C}$.

Foi utilizado o delineamento experimental inteiramente casualizado, num fatorial $6 \times 4$ (genótipo $\mathrm{x}$ tempo de embebição) com quatro repetições, considerando-se cada 50 sementes como uma unidade experimental. Após 28 dias, avaliaram-se o comprimento total das plântulas $(\mathrm{cm})$, a altura das plântulas $(\mathrm{cm})$, o comprimento de raiz $(\mathrm{cm})$, a porcentagem de germinação, o índice de velocidade de emergência (IVE) (Maguire, 1962) e a massa da matéria seca total das plântulas (mg). Os dados foram submetidos à análise de variância e a comparação de médias pelo teste de Tukey $(\alpha=0,05)$, para fator qualitativo, e análise de regressão, para fator quantitativo. Os dados das porcentagens de germinação foram transformados em arco seno $\sqrt{\mathrm{x} / 100}$, sendo que os demais dados não sofreram transformação.

\section{Resultados e Discussão}

No primeiro experimento, a germinação das sementes iniciou-se nos genótipos 14, 31, 33 e 42, e ocorreu

Tabela 1. Progênies e cultivares de maracujazeiro (P. edulis Sims f.flavicarpa Degener) avaliadas.

\begin{tabular}{clll}
\hline Genótipo & Caracterização & Ascendência & Procedência \\
\hline 1 & Progênie de meios-irmãos & Sul Brasil & Viçosa, MG \\
2 & Progênie de meios-irmãos & (CS9 x P3) & Viçosa, MG \\
4 & Progênie de meios-irmãos & CS9 & Viçosa, MG \\
6 & Progênie de meios-irmãos & Planta 1 & Campos dos Goytacazes, RJ \\
8 & Progênie de meios-irmãos & (CY6 x Sul Brasil) & Viçosa, MG \\
10 & Progênie de meios-irmãos & CY6 & Viçosa, MG \\
12 & Progênie de meios-irmãos & (CY6 x CI6) & Viçosa, MG \\
14 & Progênie de meios-irmãos & (CT8 x Sul Brasil) & Viçosa, MG \\
15 & Progênie de meios-irmãos & (CT8 x P2) & Viçosa, MG \\
16 & Progênie de meios-irmãos & (CT8 x P3) & Viçosa, MG \\
17 & Progênie de meios-irmãos & (PA CT8) & Viçosa, MG \\
18 & Progênie de meios-irmãos & (CT8 x P1) & Viçosa, MG \\
20 & Progênie de meios-irmãos & CL6 & Viçosa, MG \\
22 & Progênie de meios-irmãos & P1 & Viçosa, MG \\
23 & Progênie de meios-irmãos & P3 & Viçosa, MG \\
24 & Progênie de meios-irmãos & P3 & Viçosa, MG \\
30 & Progênie de meios-irmãos & T12 & Viçosa, MG \\
31 & Progênie de meios-irmãos & T14 & Viçosa, MG \\
33 & Progênie de meios-irmãos & T16 & Viçosa, MG \\
36 & Progênie de meios-irmãos & T28 & Viçosa, MG \\
38 & Progênie de meios-irmãos & & Norte do Rio de Janeiro \\
39 & Progênie de meios-irmãos & & Norte do Rio de Janeiro \\
42 & Cultivar IAC 277 & & Campinas, SP \\
25 & Cultivar IAC 273 & & Campinas, SP \\
\hline
\end{tabular}


18 dias após a semeadura. Nas condições brasileiras, a germinação ocorre entre duas a quatro semanas após a semeadura, dependendo das condições climáticas, sendo que no verão o período de germinação é menor e no inverno, maior (São José, 1991).

Houve efeito dos genótipos nas variáveis número de folhas e massa da matéria seca da parte aérea (Tabela 2), além da porcentagem de germinação aos 28 dias e índice de velocidade de emergência (Figura 1). Nas variáveis porcentagem de sobrevivência, altura da parte aérea, comprimento de raiz e comprimento total das plântulas, não foi encontrado efeito significativo pelo teste F (Tabela 2). As variáveis número de folhas e massa da matéria seca, apesar de terem sido significativas ao nível de $1 \%$, não apresentaram diferenças pelo teste de agrupamento de Scott-Knott (Tabela 2).

Os resultados obtidos na porcentagem de germinação, aos 28 dias da implantação do experimento (Figura 1), mostraram que apenas cinco, das 22 progênies de meios-irmãos, apresentaram germinação acima de 50\% (genótipos 6, 14, 31, 33 e 38, com valores médios de $61,0,60,0,60,5,84,0$ e 60,5\%, respectivamente). Dentre estes, os que apresentaram maior porcentagem de germinação e maior índice de velocidade de emergência (Figura 1) foi o genótipo 33 e genótipos com germinação acima de $50 \%$.

Segundo Tekrony \& Egli (1991), o vigor das plântulas, observado no campo pela habilidade da semente em emergir e crescer rapidamente e vigorosamente, é um fator que pode influenciar na produtividade das culturas.

De acordo com Melo et al. (2000), a médio e longo prazo, o melhoramento genético de Passiflora spp. deverá selecionar plantas dentro das populações, considerando-se a taxa de germinação das sementes, além de outras características agronômicas.

Os sete genótipos com menor porcentagem de germinação são descendentes das plantas CT8 (genótipos 15, 16, 17 e 18), CS9 (genótipo 4) ou CY6 (genótipo 8) (Figura 1). Estas plantas provêm de cruzamentos realizados dentro da progênie $\mathrm{BD}$, resultante de

Tabela 2. Dados médios de sobrevivência (S), número de folhas (NF), altura de parte aérea (APA), comprimento de raiz (CR), comprimento total (CT) e massa da matéria seca de plântulas (MSP) de 22 progênies e duas cultivares de maracujazeiro (P. edulis Sims f. flavicarpa Degener) ${ }^{(1)}$.

\begin{tabular}{|c|c|c|c|c|c|c|}
\hline Genótipo & S (\%) & $\mathrm{NF}$ & APA $(\mathrm{cm})$ & $\mathrm{CR}(\mathrm{cm})$ & $\mathrm{CT}(\mathrm{cm})$ & MSP (mg) \\
\hline 1 & 71,47 & $2,7 a$ & 2,7 & 4,0 & 8,0 & $0,167 \mathrm{a}$ \\
\hline 2 & 92,39 & $2,7 \mathrm{a}$ & 2,4 & 6,6 & 9,1 & $0,575 \mathrm{a}$ \\
\hline 4 & 81,14 & $2,8 \mathrm{a}$ & 2,7 & 6,3 & 9,0 & $0,330 \mathrm{a}$ \\
\hline 6 & 76,83 & $3,0 \mathrm{a}$ & 2,9 & 6,7 & 9,7 & $0,627 \mathrm{a}$ \\
\hline 8 & 59,72 & $2,0 \mathrm{a}$ & 2,9 & 5,7 & 8,7 & $0,090 \mathrm{a}$ \\
\hline 10 & 84,61 & $2,6 \mathrm{a}$ & 3,0 & 5,8 & 8,9 & $0,390 \mathrm{a}$ \\
\hline 12 & 76,60 & $3,0 \mathrm{a}$ & 2,7 & 6,4 & 9,2 & $0,177 \mathrm{a}$ \\
\hline 14 & 68,77 & $3,3 a$ & 3,0 & 7,6 & 10,7 & $0,652 \mathrm{a}$ \\
\hline 15 & 78,33 & $2,9 a$ & 2,9 & 5,3 & 8,3 & $0,077 \mathrm{a}$ \\
\hline 16 & 84,22 & $2,7 \mathrm{a}$ & 2,9 & 6,3 & 9,2 & $0,277 \mathrm{a}$ \\
\hline 17 & 88,89 & $2,5 \mathrm{a}$ & 2,6 & 6,8 & 9,4 & $0,267 \mathrm{a}$ \\
\hline 18 & 70,00 & $1,8 \mathrm{a}$ & 1,8 & 4,5 & 6,4 & $0,090 \mathrm{a}$ \\
\hline 20 & 86,40 & $2,7 \mathrm{a}$ & 2,9 & 4,8 & 9,0 & $0,327 \mathrm{a}$ \\
\hline 22 & 66,95 & $2,6 a$ & 2,4 & 5,8 & 8,3 & $0,532 \mathrm{a}$ \\
\hline 23 & 82,02 & $2,9 a$ & 2,9 & 6,4 & 9,4 & $0,412 \mathrm{a}$ \\
\hline 24 & 88,24 & $2,7 \mathrm{a}$ & 2,8 & 6,6 & 9,4 & $0,502 \mathrm{a}$ \\
\hline 25 & 78,02 & $2,8 \mathrm{a}$ & 2,4 & 6,3 & 8,7 & $0,342 \mathrm{a}$ \\
\hline 30 & 83,96 & $2,6 a$ & 3,0 & 5,7 & 8,8 & $0,385 a$ \\
\hline 31 & 87,10 & $3,0 \mathrm{a}$ & 3,2 & 6,7 & 9,9 & $0,867 \mathrm{a}$ \\
\hline 33 & 85,74 & $3,0 \mathrm{a}$ & 2,7 & 6,8 & 9,6 & $1,032 \mathrm{a}$ \\
\hline 36 & 68,99 & $2,8 \mathrm{a}$ & 2,9 & 6,2 & 9,2 & $0,445 \mathrm{a}$ \\
\hline 38 & 67,83 & $3,0 \mathrm{a}$ & 2,7 & 5,4 & 9,4 & $0,620 \mathrm{a}$ \\
\hline 39 & 90,22 & $2,9 a$ & 2,6 & 6,2 & 8,8 & $0,427 \mathrm{a}$ \\
\hline 42 & 68,34 & $3,1 \mathrm{a}$ & 2,7 & 6,9 & 9,6 & $0,457 \mathrm{a}$ \\
\hline Teste F & $0,76^{\mathrm{ns}}$ & $2,27^{* * *}$ & $1,18^{\mathrm{ns}}$ & $1,23^{\mathrm{ns}}$ & $1,35^{\mathrm{ns}}$ & $3,64^{* *}$ \\
\hline $\mathrm{CV}(\%)$ & 26,66 & 15,52 & 18,75 & 23,94 & 15,07 & 59,65 \\
\hline
\end{tabular}

${ }^{(1)}$ Médias seguidas com a mesma letra, nas colunas, pertencem ao mesmo agrupamento, pelo teste de Scott-Knott, a $1 \%$ de probabilidade. ${ }^{\text {nsNão- }}$ significativo. ${ }^{* *}$ Significativo a $1 \%$ de probabilidade. 
autofecundação da planta A4. O fato de seis dos sete genótipos com menor porcentagem de germinação serem aparentados é uma indicação de que as causas dessa baixa germinação estão relacionadas à constituição genética da planta.

Maluf (1993), estudando a herdabilidade da capacidade germinativa e da dormência das sementes em Senna multifuga, informou que a variação na capacidade germinativa entre espécies, populações ou variedades, pode ser de origem genética.

Geralmente, o sucesso do plantio comercial do maracujazeiro ( $P$. edulis f. flavicarapa) está associado à seleção dos melhores genitores (Kuhne, 1968), sendo então fundamental a seleção dos melhores genótipos.

Comparando-se os resultados das progênies com as 2 cultivares comerciais (IAC 273 e IAC 277), observou-se que 8 das 22 progênies estudadas apresentaram resultados superiores de germinação e vigor (genótipos 2, 6, 14, 23, 31, 33, 36 e 38) (Figura 1).

Problemas de germinação são muito comuns no gênero Passiflora, até mesmo no maracujá-amarelo (Meletti et al., 2002). Segundo Pereira \& Dias (2000), um dos problemas enfrentados pelos produtores de maracujá está relacionado com sua propagação, realizada com sementes que apresentam baixa e desuniforme germinação, dificultando assim a formação de mudas de qualidade.

No segundo experimento, a germinação das sementes teve início com os genótipos 36 e 8, verificada 16 dias após a semeadura. Segundo Kuhne (1968), o período de germinação de sementes do maracujazeiro é extremamente irregular, podendo oscilar de dez dias a três meses.

Em todas as variáveis analisadas não foram encontradas diferenças significativas dentro dos diferentes tempos de embebição em água destilada e na interação genótipo x tempo de embebição, a qual mostrou-se significativa somente para a variável IVE (Tabela 3). Entretanto, em relação aos genótipos, detectou-se efeito significativo nas variáveis porcentagem de germinação, IVE e massa da matéria seca das plântulas (Tabela 4). Foi observado que, dentro dos genótipos 6, 8, 14 e 18, os tempos de embebição em água destilada não foram significativos. Contudo, os genótipos 36 e 42 apresentaram os melhores resultados nos tempos 48 e 24 horas de embebição, respectivamente. Já em relação ao tempo 0 e 48 horas, o melhor IVE foi alcançado com o genótipo 36 (Tabela 3). Os resultados obtidos na porcentagem de germinação mostraram que nenhum dos genótipos estudados apresentou média superior a 50\%, encontrando-se o melhor resultado nos genótipos 36 (44,11\%), 18 $(38,40 \%), 6(34,21 \%)$ e $8(28,48 \%)$. Resultados semelhantes foram obtidos quanto ao IVE. Assim, supõe-se um certo grau de correlação entre a porcentagem de germinação e o IVE dos genótipos estudados.

Quanto à massa da matéria seca total das plântulas, os genótipos 36, 6, 18, 8 e 42 apresentaram os melhores resultados, em sequiência (Tabela 4).

Segundo Morley-Bunker (1980), o mecanismo de dormência que ocorre na família Passiflorácea é o de

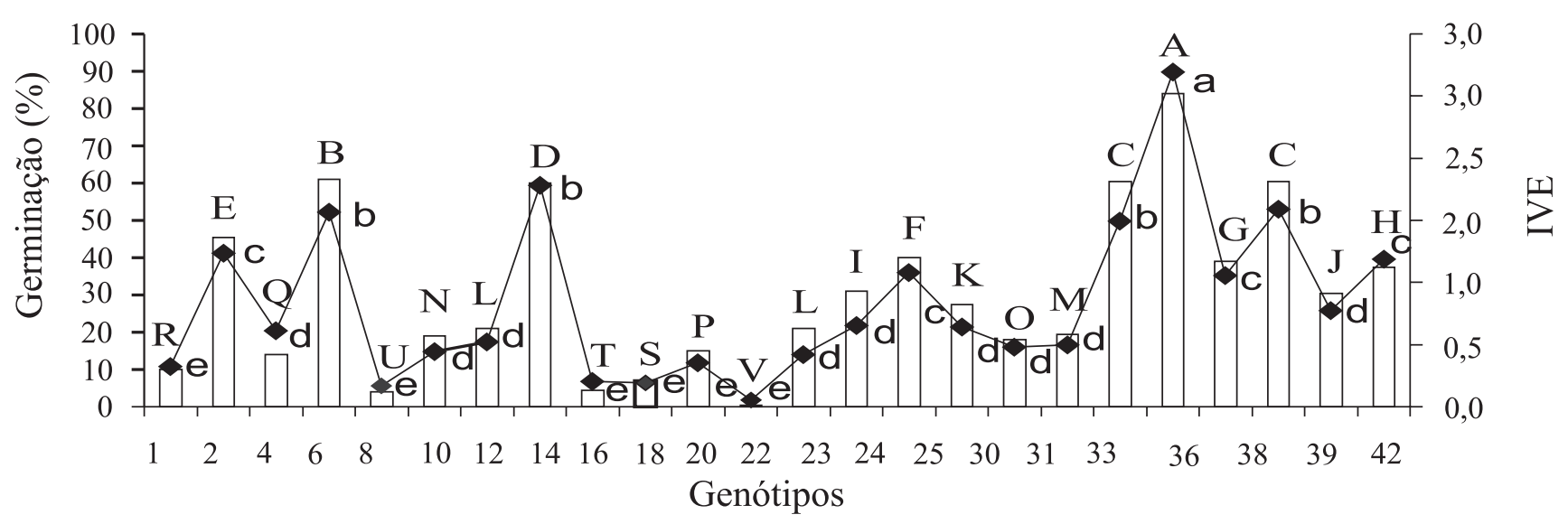

Figura 1. Germinação (\%) e índice de velocidade de emergência (IVE) (־) de sementes de 22 progênies e duas cultivares de maracujazeiro ( $P$. edulis Sims f. flavicarpa Degener). Médias com a mesma letra maiúscula (germinação) e minúscula (IVE) pertencem ao mesmo agrupamento, segundo o teste de Scott-Knott, a 1\% de probabilidade. 
Tabela 3. Índice de velocidade de emergência de seis genótipos de maracujazeiro ( $P$. edulis Sims f. flavicarpa Degener), submetidos a diferentes tempos de embebição em água destilada ${ }^{(1)}$.

\begin{tabular}{cllll}
\hline Genótipo & \multicolumn{4}{c}{ Tempo de embebição (horas) } \\
\cline { 2 - 5 } & \multicolumn{1}{c}{0} & \multicolumn{1}{c}{12} & \multicolumn{1}{c}{24} & 48 \\
\hline 6 & $0,62 \mathrm{abA}$ & $0,88 \mathrm{aA}$ & $0,65 \mathrm{aA}$ & $0,80 \mathrm{abA}$ \\
8 & $0,68 \mathrm{abA}$ & $0,94 \mathrm{aA}$ & $0,68 \mathrm{aA}$ & $0,52 \mathrm{bA}$ \\
14 & $0,27 \mathrm{bA}$ & $0,56 \mathrm{aA}$ & $0,68 \mathrm{aA}$ & $0,52 \mathrm{bA}$ \\
18 & $0,78 \mathrm{abA}$ & $0,80 \mathrm{aA}$ & $1,13 \mathrm{aA}$ & $0,69 \mathrm{bA}$ \\
36 & $1,09 \mathrm{aAB}$ & $0,98 \mathrm{aAB}$ & $0,67 \mathrm{aB}$ & $1,48 \mathrm{aA}$ \\
42 & $0,73 \mathrm{abAB}$ & $0,34 \mathrm{aB}$ & $0,99 \mathrm{aA}$ & $0,42 \mathrm{bAB}$ \\
\hline
\end{tabular}

(1)Médias seguidas pelas mesmas letras, maiúsculas nas linhas e minúsculas nas colunas, não diferem entre si, a $5 \%$ de probabilidade, pelo teste de Tukey.

Tabela 4. Porcentagem de germinação, índice de velocidade de emergência (IVE), massa da matéria seca das plântulas (MSP) de seis genótipos de maracujazeiro (P. edulis Sims f. flavicarpa Degener), submetidos a diferentes tempos de embebição em água destilada ${ }^{(1)}$.

\begin{tabular}{cclc}
\hline Genótipo & Germinação (\%) & IVE & MSP $(\mathrm{mg})$ \\
\hline 6 & $34,21 \mathrm{ab}$ & $0,74 \mathrm{ab}$ & $0,11 \mathrm{a}$ \\
8 & $28,48 \mathrm{abc}$ & $0,70 \mathrm{ab}$ & $0,08 \mathrm{ab}$ \\
14 & $19,66 \mathrm{c}$ & $0,51 \mathrm{~b}$ & $0,04 \mathrm{~b}$ \\
18 & $38,40 \mathrm{ab}$ & $0,85 \mathrm{ab}$ & $0,09 \mathrm{ab}$ \\
36 & $44,11 \mathrm{a}$ & $1,05 \mathrm{a}$ & $0,14 \mathrm{a}$ \\
42 & $24,00 \mathrm{bc}$ & $0,62 \mathrm{~b}$ & $0,08 \mathrm{ab}$ \\
\hline CV $(\%)$ & 26,75 & 46,55 & 65,47 \\
\hline
\end{tabular}

${ }^{(1)}$ Médias seguidas pelas mesmas letras nas colunas não diferem entre si, a $5 \%$ de probabilidade, pelo teste de Tukey.

controle da entrada de água para o interior da semente devido à dureza do tegumento. Apesar de os genótipos 8 e 18 apresentarem uma melhora na porcentagem de germinação de 4,0 e $0,5 \%$ ( primeiro experimento) para 28,48 e $38,40 \%$ (segundo experimento), respectivamente, todos os demais genótipos apresentaram porcentagens inferiores de germinação quando se comparou o primeiro ao segundo experimento. Supõe-se que esta redução na porcentagem esteja ligada ao tempo de embebição das sementes em água. Apesar de necessitarem de um certo grau de umidade para iniciar o processo germinativo, Gulliver \& Heydecker (1973) descrevem que quantidades excessivas de água reduzem a permeabilidade do tegumento das sementes ao oxigênio, levando à inibição da germinação.

Os resultados obtidos no primeiro e segundo experimentos sustentam a hipótese de que a porcentagem de germinação e o vigor das plântulas são fatores que devem ser levados em consideração no melhoramento do maracujazeiro.

Pesq. agropec. bras., Brasília, v.39, n.12, p.1239-1245, dez. 2004

\section{Conclusões}

1. A porcentagem de germinação e o índice de velocidade de emergência das sementes de maracujazeiro não são influenciados pelos diferentes tempos de embebição em água, mas sim pelo genótipo das plantas.

2. O genótipo 33 apresentou os maiores resultados de germinação das sementes e vigor das plântulas.

\section{Referências}

AKAMINE, E.K.; BEUMONT, J.H.; BOWERS, F.A.I.; HAMILTON, R.A.; NISHIDA, T.; SHERMAN, G.D.; SHOJI, K.; STOREY, W.B. Passion fruit culture in Hawaii. Hawaii: University of Hawaii, 1956. 35p. (Extension Circular, 245).

CARVALHO, N.M. de; NAKAGAWA, J. Sementes: ciência, tecnologia e produção. 2.ed. Campinas: Fundação Cargill, 1983. 429p.

DELOUCHE, J.C.; BASKIN, C.C. Accelerated aging techniques for predicting the relative storability of seed lots. Seed Science and Technology, v.1, p.427-452, 1973.

DIAS, D.C.F.S.; MARCOS FILHO, J. Testes de vigor baseados na permeabilidade das membranas celulares: I. Condutividade elétrica. Informativo Abrates, v.5, p.26-33, 1995.

FERREIRA, G. Estudo da embebição e do efeito de fitoreguladores na germinação de sementes de Passifloráceas. 1998. 146p. Tese (Doutorado) - Universidade Estadual Paulista, Botucatu.

FERREIRA, G. Propagação do maracujazeiro. Informe Agropecuário, v.21, p.18-24, 2000.

GULLIVER, R.L.; HEYDECKER, W. Establishment of seedlings in a changeable environment. In: HEYDECKER, W. (Ed.). Seed Ecology. London: Butterworth, 1973. p.433-462.

KUHNE, F.A. Cultivation of granadillas. Farming in South Africa, v.43, p.29-32, 1968.

LABOURIAU, L.G. A germinação das sementes. Washington: OEA, 1983. 174p.

LUNA, J.V.U. Instruções para a cultura do maracujá. Salvador: Epaba, 1984. 25p. (Circular Técnica, 7).

MAGUIRE, J.D. Speed of germination aid in selection and evaluation for emergence and vigour. Crop Science, v.2, p.176-177, 1962.

MALUF, A.M. Estudo da herdabilidade da capacidade germinativa e da dormência de sementes de Senna multifuga. Pesquisa Agropecuária Brasileira, v.28, p.1417-1423, 1993.

MELETTI, L.M.M.; FURLANI, P.R.; ÁLVARES, V.; SOARESSCOTT, M.D.; BERNACCI, L.C.; AZEVEDO FILHO, J.A. Novas tecnologias melhoram a produção de mudas de maracujá. O Agronômico, v.54, p.30-33, 2002.

MELO, A.L.; OLIVEIRA, J.C.; VIEIRA, R.D. Superação de dormência em sementes de Passiflora nitida H. B. K. com hidróxido de cálcio, ácido sulfúrico e ácido giberélico. Revista Brasileira de Fruticultura, v.22, p.260-263, 2000. 
MORLEY-BUNKER, M.J.S. Seed coat dormancy in Passiflora species. Annual Journal of the Royal New Zeland Institute of Horticulture, v.8, p.72-84, 1980.

MORLEY-BUNKER, M.J.S. Some aspects of seed dormancy with reference to Passiflora spp. and other tropical and subtropical crops. London: University of London, 1974. 43p.

PEREIRA, T.S.; ANDRADE, A.C.S. Germinação de Psidium guajava L. e Passiflora edulis Sims: efeito da temperatura, substrato e morfologia do desenvolvimento pós-seminal. Revista Brasileira de Sementes, v.16, p.58-62, 1994.

PEREIRA, K.J.C.; DIAS, D.C.F.S. Germinação e vigor de sementes de maracujá-amarelo (Passiflora edulis Sims. f. flavicarpa Deg.) submetidas a diferentes métodos de remoção da mucilagem. Revista Brasileira de Sementes, v.22, p.288-291, 2000.
PRETE, C.E.C.; GUERRA, E.P. Qualidade fisiológica das sementes. In: DESTRO, D.; MONTALVÁN, R. (Org.). Melhoramento genético de plantas. Londrina: UEL, 1999. p.661-676.

RAMOS, J.D.; CHALFUN, N.N.J.; PASQUAL, M.; RUFINI, J.C.M. Produção de mudas de plantas frutíferas por semente. Informe Agropecuário, v.23, p.64-72, 2002.

SÃO JOSÉ, A.R. Propagação do maracujazeiro. In: SÃO JOSÉ, A.R.; FERREIRA, F.R.; VAZ, R.L. A cultura do maracujá no Brasil. Jaboticabal: Unesp, 1991. p.25-41.

TEKRONY, M.D.; EGLI, D.B. Relationship of seed vigour to crop yield: a review. Crop Science, v.31, p.816-822, 1991.

VILLELA, F.A. Water relations in seed biology. Scientia Agricola, v.5, p.98-101, 1998.

Recebido em 4 de março de 2003 e aprovado em 8 de setembro de 2004 